\title{
Fatores e estratégias que impactam a aplicabilidade de organizações virtuais no setor público: a percepção dos gerentes-executivos do $\mathrm{PPA}^{1}$
}

\author{
Henrique Flávio Rodrigues da Silveira
}

\section{Introdução}

O trabalho analisa os resultados de uma pesquisa de campo realizada junto aos gerentes-executivos de programas do Plano Plurianual (PPA) sobre a possibilidade de aplicação do conceito de organização virtual no setor público. Conforme o referencial teórico que deu suporte à pesquisa, nessa nova Era de alianças e parcerias, tradicionais formas de gestão são questionadas, e o próprio conceito de "organização" está mudando, de forma a refletir os desafios inerentes ao novo ambiente.

O trabalho está estruturado em cinco tópicos. No primeiro, é apresentado o contexto que molda essa nova abordagem para o processo de planejamento governamental, seguido pela definição do problema estudado na pesquisa, e objetivos geral e específicos.

O segundo tópico apresenta o marco teórico da pesquisa e as contribuições esperadas. A metodologia está descrita no terceiro tópico. Finalmente, os resultados 
da pesquisa de campo são apresentados no quarto tópico, seguidos das conclusões no último tópico.

Entre as conclusões, destaca-se a possibilidade de aplicação, no setor público, do conceito de organizações virtuais, as quais operam necessariamente a partir do compartilhamento de recursos, informações e objetivos de organizações formalmente independentes, o que requer lidar com diferentes impressões sobre autonomia, poder e controle e diferentes culturas organizacionais, alterando, radicalmente, conceitos e práticas acerca de fronteiras organizacionais, propriedade de recursos, gestão da informação e processo decisório.

\section{Delineamento da pesquisa}

\section{Contexto}

Os desafios que as organizações enfrentam requerem cada vez mais o esforço colaborativo de várias organizações (incluindo governo, setor privado e terceiro setor), e uma efetiva ação coordenada tornou-se um imperativo. $\mathrm{Na}$ tese que originou este artigo, os estudos demonstraram a possibilidade de que essa "ação coordenada" viesse a ser exercida no escopo de uma organização virtual.

Uma organização virtual pode ser definida como uma parceria entre organizações legalmente independentes, com o propósito de conjuntamente oferecer produtos ou prover serviços aos clientes/ usuários, os quais a percebem como uma organização singular. Em uma organização virtual, os parceiros compartilham informações e infra-estrutura de maneira sinérgica, incrementando a efetividade para um nível que nenhum deles poderia alcançar sozinho.

Para compor o referencial teórico que subsidiou a realização da pesquisa de campo, foram selecionados os seguintes temas: planejamento governamental, trabalho em rede, gestão cooperativa da informação, fronteiras organizacionais, cultura organizacional, poder e controle, confiança e sistemas interorganizacionais. A partir desses temas, foram estudados os fatores e estratégias que impactam os relacionamentos interorganizacionais, e as questões que emergem quando sistemas, processos e recursos cruzam as fronteiras corporativas rumo a arenas de colaboração.

\section{Definição do problema e objetivos da pesquisa}

No novo ambiente cooperativo, é necessário promover relacionamentos estáveis e mútua confiança, maximizando benefícios e minimizando riscos, ao mesmo tempo em que desaparece ou é bastante reduzido o tradicional controle direto sobre os recursos requeridos pelos processos de negócio.

No setor público, essas questões parecem especialmente relevantes devido à forte tradição de independência das organizações públicas, o que pode comprometer a motivação das organizações públicas para a adoção de formas mais colaborativas de trabalho.

Aplicar a idéia de organização virtual ao processo de planejamento governamental significa que os gestores públicos precisam interagir com um ambiente informacional cooperativo, no qual a informação requerida estaria disponível independentemente da real estrutura hierárquica e de eventuais diferenças tecnológicas dos sistemas que fornecem a informação.

Entretanto, a despeito dos esforços do governo brasileiro para incrementar o uso da tecnologia da informação, as organizações públicas ainda constituem um imenso 
conjunto de ilhas, um verdadeiro arquipélago de siglas e territórios demarcados. De forma a alcançar maior transparência e efetividade da ação governamental, uma efetiva integração das organizações públicas e de seus sistemas é requerida, algo como a migração para uma imagem de continente, em contraponto ao arquipélago atualmente existente.

Mais que infra-estrutura tecnológica, entretanto, será necessário para viabilizar o entendimento e a aplicação do conceito de organizações virtuais no setor público. Aspectos como cultura organizacional, poder e controle, fronteiras organizacionais, confiança e gestão da informação deverão ser observados no contexto do planejamento governamental.

Assim, a pesquisa se justifica pela necessidade de aferição do grau de maturidade da gestão pública no governo federal em relação a fatores e estratégias que impactam o processo de coordenação interorganizacional, a partir da percepção dos gestores, e pelo fato de subsidiar possíveis aperfeiçoamentos na administração pública brasileira, por meio do aperfeiçoamento da coordenação interorganizacional e de uma maior ênfase em ambientes informacionais cooperativos.

O processo de planejamento governamental, desde a sua formulação até a sua implementação e avaliação, acontece em meio a uma rede de relacionamentos interorganizacionais e sociais. A gestão dessa rede de relacionamentos é afetada por fatores diversos, tecnológicos, culturais e sociais, e é preciso fazer uso de estratégias que aumentem a efetividade da ação governamental. Uma possibilidade seria a aplicação do conceito de organizações virtuais, já utilizado no setor privado, para o setor público, mormente no que se refere à gestão de programas do PPA, com destaque para os programas multisetoriais.

Assim, esta pesquisa teve como motivação principal a possibilidade de contribuir para o incremento da efetividade da ação governamental, por meio de uma maior racionalização da coordenação interorganizacional, a ser exercida no escopo de novas estruturas organizacionais, na forma de organizações virtuais aplicadas ao setor público. Para isso, foi necessária a

"Aplicar a idéia de organização virtual ao processo de planejamento governamental significa que os gestores públicos precisam interagir com um ambiente informacional cooperativo."

identificação dos principais fatores e estratégias que impactam o processo de coordenação interorganizacional em organizações virtuais, e a avaliação da percepção de gestores envolvidos com o planejamento governamental, com foco no poder executivo federal, sobre os já referidos fatores e estratégias.

A pesquisa norteou-se pelas seguintes questões: 
- Quais são os principais fatores e estratégias que impactam o processo de coordenação interorganizacional em organizações virtuais?

- Qual a percepção de gestores envolvidos no planejamento governamental, com foco no poder executivo federal, quanto aos fatores e estratégias identificados na literatura e que impactam o processo de coordenação interorganizacional em organizações virtuais?

- O que pode ser feito para incrementar a efetividade da ação governamental, a partir de uma maior racionalização da coordenação interorganizacional, a ser exercida no escopo de novas estruturas organizacionais, na forma de organizações virtuais aplicadas ao setor público?

O objetivo geral da pesquisa é definir diretrizes que contribuam para o incremento da efetividade da ação governamental, por meio de uma maior racionalização da coordenação interorganizacional, a ser exercida no escopo de novas estruturas organizacionais, na forma de organizações virtuais aplicadas ao setor público.

Como objetivos específicos, a pesquisa apresenta:

- Identificar, a partir do referencial teórico, os principais fatores e estratégias que impactam o processo de coordenação interorganizacional em organizações virtuais;

- Aferir a percepção de gestores envolvidos com a implementação do planejamento governamental, com foco no poder executivo federal, em relação aos fatores e estratégias que impactam o processo de coordenação interorganizacional em organizações virtuais.

\section{Referencial teórico}

Sobre o marco teórico da pesquisa, o autor desenvolveu estudos (que podem ser compulsados a partir da versão integral da tese que originou este artigo) para conhecer mais sobre a possibilidade de aplicação do conceito de organização virtual no planejamento do setor público. Tais estudos demonstraram que a gestão dos ambientes informacionais cooperativos, necessários para maior efetividade da ação de governo, irá requerer muito além de aspectos tecnológicos - será necessário um arcabouço teórico-metodológico, multidisciplinar, incluindo aspectos culturais e comportamentais.

Assim, e sempre sob a ótica dos relacionamentos interorganizacionais, foram desenvolvidos estudos sobre os seguintes tópicos:

- planejamento governamental políticas públicas, NPM (new public management), governança, accountability, implementação de políticas, descentralização x centralização x devolution, avaliação do processo de implementação e de seus resultados, coordenação interorganizacional;

- planejamento governamental no Brasil;

- trabalho em rede;

- gestão "cooperativa" da informação;

- fronteiras organizacionais;

- cultura organizacional: gentes e gerentes;

- poder e controle;

- confiança;

- sistemas interorganizacionais.

Como contribuição da pesquisa, registre-se que não foram encontrados estudos que conectem o processo de planejamento governamental ao conceito de organização virtual e aspectos correlatos, especificamente coordenação interorganizacional, trabalho em rede, gestão da informação, cultura organizacional, poder e controle, fronteiras 
organizacionais, confiança e sistemas interorganizacionais.

Dessa forma, as esperadas contribuições desta pesquisa são o preenchimento de uma lacuna de conhecimento (fatores e estratégias que impactam a coordenação interorganizacional no contexto do planejamento governamental), e o fornecimento de sugestões no âmbito do processo de planejamento governamental de forma a incrementar a efetividade do processo de coordenação interorganizacional por meio da discussão sobre o entendimento e a aplicabilidade do conceito de organização virtual no setor público. Sinteticamente:

- aumentar a base de conhecimentos sobre o assunto;

- subsidiar possíveis aperfeiçoamentos na administração pública brasileira, por meio do aperfeiçoamento da coordenação interorganizacional e da maior ênfase em ambientes informacionais sob uma nova abordagem, que valoriza parcerias e colaboração.

As conclusões dos estudos desenvolvidos pelo autor para compor o referencial teórico evidenciaram que a migração da forma tradicional de planejar e gerir em direção a uma nova abordagem colaborativa, com novos benefícios e novos riscos, implica a aceitação de um novo paradigma, um novo modelo, com outra configuração e outras regras. Mas todas essas mudanças devem motivar algum tipo de resistência, pois para enfrentar esse desafio, talvez sejam necessários não apenas novos ambientes informacionais, mas também novas organizações. Mas como seria esta "nova organização" que é requerida pelo novo paradigma?

Sobre isso, existe uma profusão de termos correntemente usados para descrever a nova organização: organização ágil, organização em rede, organização vir- tual, organização extendida (extended enterprise), organização do conhecimento (knowledge enterprise), organização do aprendizado (learning organization), e organização "inteligente" (smart organization) (ALADWANI, 2002; Baker et al, 2002; Bradner, 2003; Burnett, 2000; Camarinha-Matos; Afsarmanesh; Rabelo, 2001; Carbo; Molina; Davila, 2003; Castelfranchi, 2002; Devine; Filos, 2001; Filos; BANAHAN, 2001; GORANSON, 2001; INKPEN; Ross, 2001; Merali, 2002; Molina; FloRES, 2001; Ricci, 2002; RiempP, 1998; Shumar; RenNinger, 2002; Silva; Rocha, 2001; Mundim; Bremer, 2001).

A partir dos estudos efetuados, foi exercida a opção pelo termo "organização virtual", a qual é definida, para efeito desta pesquisa, como uma parceria entre organizações legalmente independentes, com o propósito de conjuntamente oferecer produtos ou prover serviços aos clientes/ usuários, os quais a percebem como uma organização singular. Em uma organização virtual, os parceiros compartilham informações e infra-estrutura de maneira sinérgica, incrementando a efetividade para um nível que nenhum deles poderia alcançar sozinho.

Ainda a partir do referencial teórico, foram identificados os principais fatores que impactam positivamente a coordenação interorganizacional em organizações virtuais:

- processos de avaliação das organizações que contemplam resultados coletivos e não apenas de uma organização;

- compartilhamento do processo decisório;

- compartilhamento de recursos humanos, tecnológicos e informacionais;

- linguagem e significados comuns;

- conhecimento técnico para implementação de práticas cooperativas de trabalho; 
- infra-estrutura tecnológica adequada;

- recursos humanos com conhecimentos e habilidades para trabalho em equipes interorganizacionais e multidisciplinares;

- processos de avaliação de recursos humanos que estimulam o trabalho cooperativo;

- recursos humanos conscientes dos objetivos comuns da parceria, externos às suas organizações;

- recursos humanos conscientes do que está sendo desenvolvido externamente às suas organizações, relacionado à parceria.

Foram também identificados os principais fatores que estimulam a participação em organizações virtuais:

- redução de custos;

- compartilhamento de informações;

- melhoria da qualidade dos produtos/ serviços;

- aumento da produtividade.

Pelo fato da pesquisa de campo ter como público-alvo gestores de programas governamentais, com foco no poder executivo federal, um outro fator foi elencado como estimulante à participação em organizações virtuais: "o cumprimento de orientação geral do governo”, ainda que não tenha sido recorrentemente citado nos trabalhos consultados.

O exame da literatura também possibilitou a identificação dos principais fatores que são cruciais para o sucesso de uma organização virtual:

- confiança entre os parceiros;

- contratos interorganizacionais formais detalhando as responsabilidades de cada participante;

- compromisso com a parceria;

- percepção dos parceiros de que os benefícios superam os custos e a relativa perda de autonomia;

- estratégia e objetivos bem definidos e adequadamente divulgados.
A literatura pesquisada também permitiu a identificação das prinicipais estratégias que poderiam ser desenvolvidas para aumentar o nível de comprometimento das organizações envolvidas em uma organização virtual:

- implementar sistemas que permitam a efetiva mensuração da contribuição de cada um dos parceiros na busca dos objetivos comuns;

- desenvolver as relações interpessoais;

- implementar política de comunicações abertas e freqüentes;

- prover recursos segundo critérios objetivos com base no desempenho de cada um dos parceiros;

- prover oportunidades de treinamento e de desenvolvimento profissional de forma equilibrada para todos os parceiros.

$\mathrm{O}$ mesmo se aplica para as principais estratégias que podem ser desenvolvidas para aumentar as chances de sucesso de uma organização virtual no setor público:

- harmonizar estruturas organizacionais e políticas de pessoal;

- implementar sistemas de auditoria e de avaliação de desempenho que estimulem práticas cooperativas;

- estabelecer objetivos comuns a serem alcançados apenas por meio de trabalho cooperativo;

- prover infra-estrutura tecnológica adequada;

- integrar as parcelas dos orçamentos das organizações envolvidas de modo a permitir uma gestão compartilhada do "orçamento" da organização virtual.

\section{Metodologia}

A pesquisa de campo foi realizada por meio de questionário eletrônico, "hospedado" em um provedor na Internet, de forma a evitar a circulação, ainda que 
eletrônica, de arquivos entre o pesquisador e os respondentes. O questionário foi dividido em três partes, com 19 questões no total. A primeira parte, com cinco questões, buscou identificar o perfil dos respondentes. A segunda parte, com dez questões, abordou questões referentes às organizações e aos servidores públicos, e foi utilizada uma escala Likert de quatro pontos. A terceira parte, com quatro itens, trouxe questões para aferir a percepção sobre fatores e estratégias, identificados a partir do referencial teórico, que impactam a coordenação interorganizacional.

Quanto ao universo da pesquisa, em setembro de 2005, o PPA era composto por 408 programas, divididos em cinco categorias: 333 - finalísticos; 46 - gestão de políticas públicas; 17 - serviços ao estado; 10 - operações especiais; 2 - apoio administrativo.

A partir de estudos desenvolvidos sobre a natureza dos programas, foram desconsiderados 72 programas, por se enquadrarem em uma das seguintes situações: programas do tipo "operações especiais" - 10; programas de outras áreas que não o poder executivo federal 11; programas em processo de extinção (restos a pagar) - 16; programas relacionados a atividades padronizadas, inclusive de serviços - 7; programas referentes a processos internos às organizações (ensino, saúde, etc.) - 16; programas desenvolvidos com autonomia por empresas estatais e privadas -12 .

O universo total, então, passou a ser de 336 programas. Foram ainda desconsiderados do universo, apenas para efeito de mensuração do tamanho da amostra, 75 programas para os quais os documentos consultados apontavam um gerenteexecutivo já cadastrado em outro programa, ou, na ausência deste, um mesmo gerente. Com isso, evitou-se considerar respostas duplicadas, já que o sujeito da pesquisa era o gestor (gerente-executivo ou gerente), e não o programa. Assim, o universo ficou constituído de 261 programas.

Para cálculo da amostra foi utilizada a seguinte fórmula:

$$
\mathrm{n}=\left(\mathrm{d}^{2} \times \mathrm{p} \times \mathrm{q} \times \mathrm{N}\right) /\left(\mathrm{e}^{2} \mathrm{x}(\mathrm{N}-1)+\mathrm{d}^{2} \times \mathrm{p} \times \mathrm{q}\right)
$$

Em que: $d=$ valor da distribuição normal para o nível de confiança de 95\%

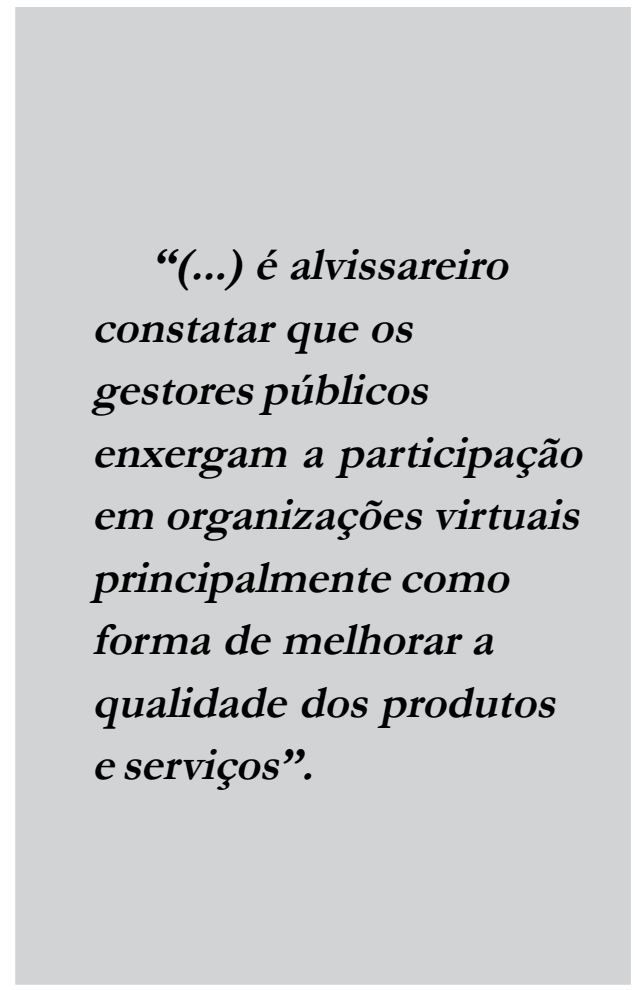

$(\mathrm{d}=2)$; características da população (foram utilizados $\mathrm{p}=50$ e $\mathrm{q}=50) ; \mathrm{N}=$ tamanho do universo (=261); e $=$ erro amostral tolerável $(=5,5 \%)$.

O nível de confiança adotado (95\%) e o erro amostral tolerável (5,5\%) são considerados válidos para pesquisas em Ciências Sociais. Com isso, o tamanho calculado da amostra foi de 146, correspondente a 56\% do universo (261). 


\section{Questionário}

Parte II - Organizações públicas e servidores públicos (o termo "servidores públicos" compreende ocupantes de cargos efetivos e ocupantes de cargos em comissão)

Por favor, expresse o seu grau de concordância/discordância com as afirmações apresentadas de acordo com as seguintes opções: discordo totalmente, discordo, mais do que concordo, concordo mais do que discordo, concordo totalmente.

6 - Os processos de avaliação das organizações públicas consideram o envolvimento e o compromisso com outras organizações e com os resultados coletivos do governo, e não apenas os resultados da própria organização.

7 - No desenvolvimento de ações que envolvem mais de uma organização, as decisões são tomadas de forma compartilhada.

8 - No desenvolvimento de ações que envolvem mais de uma organização, as organizações públicas compartilham recursos humanos, tecnológicos e informacionais.

9 - Os conceitos e termos utilizados no processo de planejamento governamental têm os mesmos significados e aplicações para as organizações envolvidas.

10 - As organizações públicas detêm suficiente conhecimento técnico para a implementação de práticas cooperativas de trabalho por meio de parcerias.

11 - As organizações públicas possuem uma adequada infra-estrutura tecnológica para a implementação de práticas cooperativas de trabalho por meio de parcerias.

12 - Os servidores públicos envolvidos na execução do programa gerenciado por V.Sa. detêm conhecimentos e habilidades para trabalhar em equipes interorganizacionais e multidisciplinares.

13 - Os processos de avaliação de desempenho dos servidores públicos envolvidos na execução do programa gerenciado por V.Sa. levam em conta os resultados coletivos do governo, e não apenas os resultados de suas próprias organizações.

14 - Os servidores públicos envolvidos na execução do programa gerenciado por V.Sa. conhecem os objetivos do governo para a área de atuação de suas organizações e não apenas os objetivos de suas próprias organizações.

15 - Os servidores públicos envolvidos na execução do programa gerenciado por V.Sa. conhecem o trabalho correlacionado desenvolvido em outras organizações e que pode ter impacto em suas áreas de atuação, e não apenas o que está sendo feito em suas próprias organizações.

\section{Resultados da pesquisa e análise dos dados}

Foram coletadas 168 respostas, das quais 12 tiveram que ser excluídas, por se referirem a programas excluídos do universo, como já explicado. Foram obtidas, assim, 156 respostas válidas, correspondentes a $59,8 \%$ do universo (261) e a $106,8 \%$ da amostra (146).
Sobre o perfil dos respondentes (Parte I do questionário), cabe destacar a forte presença do sexo feminino (um terço do total), dos adultos jovens (um terço dos gerentes-executivos têm até 40 anos), da alta escolaridade (dois terços são pós-graduados) e destaca-se também o tempo relativamente curto de serviço público (um terço tem até dez anos de serviço público). Esses dados podem 


\section{Questionário}

\section{Parte III - Fatores e estratégias}

Por favor, em cada questão classifique as opções apresentadas utilizando uma escala de 1 a 5, a partir do "mais importante" (1) para o "menos importante" (5).

16 - Classifique os seguintes fatores que poderiam estimular a participação de uma organização pública em uma organização virtual.

por favor, utilize uma escala de 1 a 5, a partir do "mais importante" (1) para o "menos importante" (5)

( ) Redução de custos

( ) Compartilhamento de informações

( ) Melhoria da qualidade dos produtos/serviços

( ) Cumprimento de orientação geral do governo

( ) Aumento da produtividade

17 - Classifique os seguintes fatores segundo o grau de importância para o sucesso de uma organização virtual no setor público.

por favor, utilize uma escala de 1 a 5, a partir do "mais importante" (1) para o "menos importante" (5)

( ) Confiança entre os parceiros

( ) Contratos interorganizacionais formais detalhando as responsabilidades de cada participante

( ) Compromisso com a parceria

( ) Percepção dos parceiros de que os benefícios superam os custos e a relativa perda de autonomia

( ) Estratégia e objetivos bem definidos e adequadamente divulgados

18 - Classifique as seguintes estratégias que poderiam ser desenvolvidas para aumentar o nível de comprometimento das organizações envolvidas em uma organização virtual no setor público. por favor, utilize uma escala de 1 a 5, a partir do "mais importante" (1) para o "menos importante" (5) ( ) Implementar sistemas que permitam a efetiva mensuração da contribuição de cada um dos parceiros na busca dos objetivos comuns

( ) Desenvolver as relações interpessoais

( ) Implementar política de comunicações abertas e freqüentes

( ) Prover recursos segundo critérios objetivos com base no desempenho de cada um dos parceiros

( ) Prover oportunidades de treinamento e de desenvolvimento profissional de forma equilibrada para todos os parceiros

19 - Classifique, segundo o grau de importância, as seguintes estratégias que poderiam ser desenvolvidas para aumentar as chances de sucesso de uma organização virtual no setor público.

por favor, utilize uma escala de 1 a 5 , a partir do "mais importante" (1) para o "menos importante" (5)

( ) Harmonizar estruturas organizacionais e políticas de pessoal

( ) Implementar sistemas de auditoria e de avaliação de desempenho organizacional que estimulem práticas cooperativas

( ) Estabelecer objetivos comuns a serem alcançados apenas por meio de trabalho cooperativo

( ) Prover infra-estrutura tecnológica adequada

( ) Integrar as parcelas dos orçamentos das organizações envolvidas de modo a permitir uma gestão compartilhada do "orçamento" da organização virtual 
indicar certa "oxigenação" na gestão do planejamento governamental, o que apenas poderia ser confirmado de fato confrontando-se dados históricos, o que não seria possível fazer especificamente com a figura dos gerentes-executivos, criada apenas em 2004.

De qualquer forma, uma comparação no âmbito do PPA é possível a partir de um documento divulgado em 2002 pelo Ministério do Planejamento, no qual constava que apenas um em cada cinco (19\%) gerentes de programa do PPA 2000-2003 era do sexo feminino. Apesar de o documento fazer referência à função de gerente, e não de gerente-executivo (criado apenas em 2004), a relação atual (um em três) mostra uma forte participação das mulheres na gestão do PPA.

Ainda de acordo com o documento supracitado, e com a mesma ressalva sobre as diferenças com o público-alvo desta pesquisa, o percentual de gerentes do PPA 2000-2003 com idades entre "40 e 50 anos" era de 50\%, contra 43,6\% para esta pesquisa, que também apontou $32,7 \%$ dos gerentes-executivos com até 40 anos.

Já os resultados encontrados quanto à escolaridade mantêm coerência com os resultados da pesquisa de 2002 (novamente, destaque-se a diferença entre os públicosalvo), que apontou que em $200231 \%$ dos gerentes tinham mestrado (18\%) ou doutorado (13\%). Atualmente, 32,1\% dos gerentes-executivos têm mestrado ou doutorado. A pesquisa de 2002 também apontou que todos os gerentes tinham diploma de nível superior, dado que foi praticamente o mesmo para os atuais gerentes-executivos, dos quais 99,4\% têm nível superior.

Quanto às diferenças entre os sexos, pode-se destacar o fato de que há mais mulheres jovens $(43,1 \%$ das mulheres têm até 40 anos, contra 27,6\% dos homens), com menos tempo de serviço $(43,1 \%$ das mulheres com até 10 anos de serviço, contra $28,5 \%$ dos homens) e sem vínculo permanente $(41,2 \%$ das mulheres contra $18,1 \%$ dos homens), ocupando a função de gerente-executivo do que homens, o que pode indicar potencial de crescimento da participação das mulheres na gestão do planejamento governamental.

De fato, se entre os gerentes-executivos com mais de trinta anos de serviço público, as mulheres representam apenas $27,3 \%$, na faixa de até cinco anos de serviço público as mulheres já representam $46,2 \%$.

Os gerentes-executivos sem vínculo permanente com o serviço público são um pouco mais jovens que seus pares de carreira do executivo federal $(37,5 \%$ têm até 40 anos, contra 33\% dos servidores de carreira do executivo), e têm menos tempo de serviço público, o que é coerente com sua situação de não vinculação permanente com o serviço público (57,5\% têm até dez anos, contra $29 \%$ dos servidores de carreira do executivo).

Quanto à qualificação, observa-se maior qualificação acadêmica dos gerentesexecutivos sem vínculo permanente com o serviço público, com $40 \%$ deles com mestrado ou doutorado, contra $28 \%$ dos servidores de carreira do executivo federal.

Interessante registrar que, considerando-se todos os gerentes-executivos, há semelhança entre os percentuais de mestres e doutores na faixa de até cinco anos de serviço público $(34,6 \%)$ e na faixa acima de 30 anos de serviço público (36,3\%), o que sugere que muitos gerentes-executivos com pouco tempo de serviço já ingressaram no serviço público com titulação stricto sensu.

Com relação à Parte II do questionário (questões seis a 15), que registrou opiniões 
sobre a ocorrência dos fatores que impactam positivamente a coordenação interorganizacional em organizações virtuais, os resultados mostram curiosa semelhança entre os percentuais de "discordo totalmente" (13,8\%) e "concordo totalmente" (12,7\%), e também mostra certo equilíbrio entre "discordo mais do que concordo" (39,0\%) contra "concordo mais do que discordo" (34,6\%), o que resultou em 52,8\% para a discordância e 47,2\% para a concordância.

Serão inicialmente analisadas as seis questões que apresentaram percentuais de discordância maiores que de concordância, e depois as quatro questões com percentuais de concordância maiores que de discordância.

O maior percentual de discordância aconteceu na questão 13 , com 74,4\%. Os gerentes-executivos discordaram fortemente em relação à adequação dos processos de avaliação de desempenho dos servidores públicos que, para terem impacto positivo na coordenação interorganizacional em organizações virtuais, deveriam levar em conta os resultados coletivos do governo, e não apenas os resultados das próprias organizações em que trabalham os servidores.

Esse alto grau de discordância foi verificado também em todas as estratificações efetuadas (sexo, faixa etária, escolaridade/titulação, vínculo com o serviço público e tempo de serviço público), e em nenhuma delas o índice de discordância com relação a esse item foi inferior a $61,1 \%$ (caso dos gerentes-executivos na faixa etária de 51 a 60), chegando a até a 87,5\% (caso dos gerentes-executivos que são servidores de carreira de outros órgãos que não aqueles vinculados ao poder executivo federal).

A preocupação com a inadequação dos processos de avaliação dos servidores públicos, no tocante ao estímulo à coordenação interorganizacional em organizações virtuais, também é confirmada pelo fato de os gerentes-executivos na faixa etária de 51 a 60 anos, que previsivelmente também compõem o grupo dos que têm mais de 30 anos de serviço público.

A questão 11 recebeu o segundo maior percentual de discordância $(62,2 \%)$ e abordou a adequação da infra-estrutura tecnológica para a implementação de práticas cooperativas de trabalho por meio de parcerias. $\mathrm{O}$ estrato que apresentou o maior percentual de discordância $(71,4 \%)$ em relação à adequação da infra-estrutura tecnológica foi o de gerentes-executivos com até 30 anos de idade, e o que apresentou o menor percentual de discordância foi, novamente, o grupo de gerentes-executivos com idade entre $51 \mathrm{e}$ 60 anos $(52,8 \%)$.

O terceiro maior percentual de discordância $(59,6 \%)$ ficou com a questão oito, que tratou do compartilhamento de recursos humanos, tecnológicos e informacionais por ocasião do desenvolvimento de ações que envolvem mais de uma organização pública. O estrato que apresentou o maior percentual de discordância (90,5\%) em relação ao compartilhamento de recursos foi, novamente, o de gerentesexecutivos com até 30 anos de idade, e o que apresentou o menor percentual de discordância foi, de novo, o grupo de gerentes-executivos com idade entre 51 e 60 anos $(47,2 \%)$.

O percentual de discordância quanto à adequação dos processos de avaliação das organizações públicas para que sejam considerados o envolvimento e o compromisso com outras organizações e com os resultados coletivos do governo, e não apenas os resultados da própria organização, objeto da questão seis, foi de 56,4\%, 
ocupando o quarto lugar geral em discordância. Quem mais discordou do item foram os gerentes-executivos com até 30 anos de idade, com $66,7 \%$, e o menor percentual, $45,2 \%$, foi registrado pelos gerentes-executivos que têm entre 21 e 30 anos de serviço público.

Assim como os processos de avaliação dos servidores, também os processos de avaliação das organizações envolvidas em arranjos colaborativos precisam ser desenhados de modo a estimular práticas cooperativas, de forma a estimular o envolvimento em parcerias interorganizacionais.

Sobre o conhecimento técnico para a implementação de práticas cooperativas de trabalho por meio de parcerias, aferido pela questão 10 , o percentual geral de discordância ficou em 55,8\%, ocupando o quinto lugar em discordância. Quem mais discordou sobre o item foram os gerentes-executivos com menos tempo de serviço público (até cinco anos), que inclusive o colocaram em primeiro lugar em discordância, e o menor percentual ficou, outra vez, com os gerentes-executivos com mais de 30 anos de serviço público, com 40,9\% de discordância.

A concentração da posição relativa do item, mostra convergência de opiniões quanto à percepção de discordância com relação à existência de conhecimentos especializados nas organizações públicas para a implementação de práticas cooperativas de trabalho por meio de parcerias.

A última questão, por ordem decrescente de discordância, em que o percentual de discordância superou o percentual de concordância foi a questão sete (sexto lugar, com 52,6\%), que indagou sobre o compartilhamento de decisões em relação a ações que envolvem mais de uma organização. Os gerentes-executivos que registraram a maior discordância $(61,0 \%)$ foram os que detêm a titulação de mestre, e os que apontaram a menor discordância foram os servidores de carreira de outros órgãos, com 31,3\%.

Com relação às quatro questões nas quais os percentuais de concordância superaram os percentuais de discordância, o mais alto percentual de concordância $(71,2 \%)$ ocorreu com o fator da questão 12, que afirma que os servidores públicos detêm conhecimentos e habilidades para trabalhar em equipes interorganizacionais e multidisciplinares. Este fator também ficou em primeiro lugar como o maior percentual de concordância em todas as 18 estratificações feitas, com percentuais variando de $66,7 \%$ (caso dos doutores) a 93,8\% (servidores sem vínculo permanente com o serviço público).

O reconhecimento pelos gestores de que os servidores detêm conhecimentos e habilidades para trabalhar em equipes interorganizacionais e multidisciplinares é importante para que novos arranjos colaborativos sejam estruturados de forma sustentável. Esse reconhecimento aumenta a responsabilidade na condução do planejamento governamental, por incrementar as possibilidades de que novas formas de articulação interorganizacional sejam possíveis, com as dificuldades residindo em outros aspectos, que não no corpo de servidores.

A questão 14 apresentou o segundo maior percentual de concordância, com $57,1 \%$ contra $47,2 \%$ do índice geral de concordância, e indagou sobre o conhecimento, por parte dos servidores, dos objetivos do governo para a área de atuação das organizações onde atuam. $\mathrm{O}$ percentual de concordância mais alto para esse fator $(76,2 \%)$ foi proporcionado pelos gerentes-executivos com até 30 anos de idade, e o menor $(43,3 \%)$ pela faixa etária de 31 a 40 anos. 
Ou seja, para os gerentes-executivos, os servidores conhecem o que o governo pretende para a área em que atuam, e isso é relevante para arranjos colaborativos porque a sensação de contribuição para o alcance de objetivos comuns é importante fator motivacional.

O terceiro maior percentual de concordância, 53,2\%, ficou com a questão nove, que perguntou se os conceitos e os termos utilizados no processo de planejamento governamental têm os mesmos significados e aplicações para as organizações envolvidas. O maior percentual de concordância para o fator $(63,3 \%)$ foi registrado pelos gerentes-executivos com idade entre 31 e 40 anos, e o menor $(33,3 \%)$ foi registrado pelos doutores.

A distribuição por estratos mostrou que, diferentemente do que aconteceu para o primeiro e o segundo maiores percentuais de concordância, para o terceiro maior percentual não houve convergência de opiniões entre os estratos verificados.

Assim, a harmonia entre conceitos e significados é percebida de forma muito diferente entre os gerentes-executivos, refletindo a complexidade do tema e a dificuldade de lidar com ele, especialmente em ambientes interorganizacionais, nos quais "linguagens" organizacionais diversas entram em contato (e às vezes em choque).

Dessa forma, para além do simples compartilhamento de um sistema de códigos, é necessário que os processos de comunicação levem em conta diferentes contextos e culturas organizacionais, se o propósito é o compartilhamento não de símbolos mas de significados.

O quarto maior percentual de concordância $(51,9 \%)$, e último superior ao percentual de discordância, refere-se à questão 15, que indagou sobre o conhecimento, por parte dos servidores, do trabalho correlacionado desenvolvido em outras organizações e que pode ter impacto em suas áreas de atuação. Os gerentes-executivos que mais concordaram com o item foram aqueles com até 30 anos de idade (71,4\%), e o menor percentual de concordância (31,3\%) foi registrado pelo grupo de gerentes-executivos que são servidores de carreira de outros órgãos que não aqueles vinculados ao poder executivo federal.

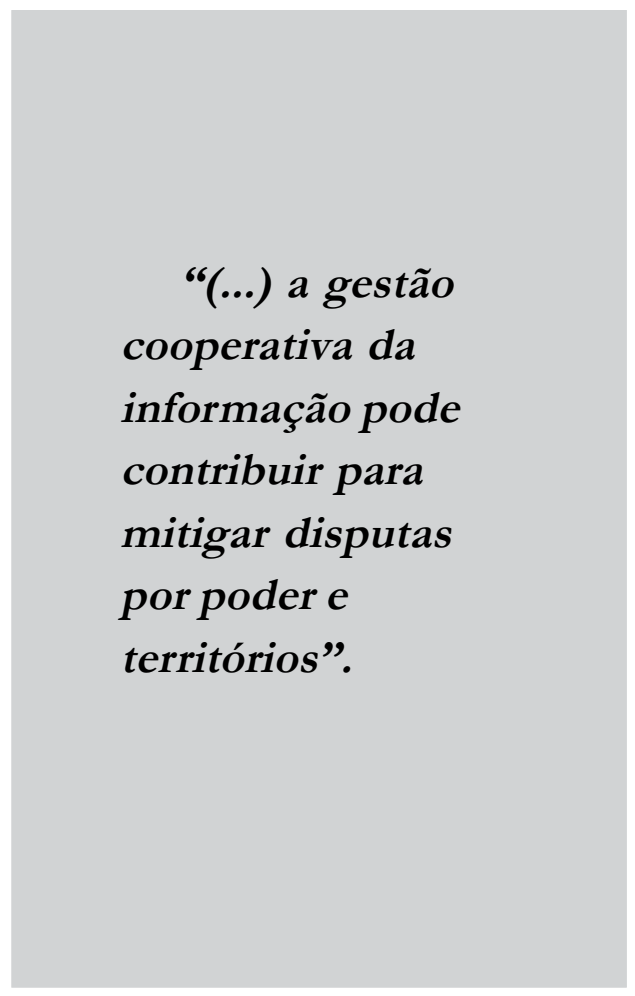

Assim como a constatação de que os gestores consideram que os servidores detêm conhecimentos e habilidades para trabalhar em equipes interorganizacionais e multidisciplinares, a percepção de que os servidores conhecem o que acontece para além de suas fronteiras organizacionais também significa que, na visão dos gestores, a estruturação de novos arranjos colaborativos de forma 
sustentável é possível no que depender dos servidores, sendo necessário, porém, alterar estruturas e sistemas.

A Parte III buscou captar as percepções dos gerentes-executivos quanto a fatores e estratégias relacionados ao conceito de organizações virtuais aplicado ao setor público. De forma análoga à análise da Parte I, será apresentada inicialmente uma análise questão por questão, seguida de uma análise a partir das estratificações efetuadas.

A questão 16 apresentou o fator "melhoria da qualidade dos produtos/ serviços" como o fator mais importante para estimular a participação de uma organização pública em organizações virtuais, com 16,0\% do total possível de pontos. $\mathrm{O}$ fato de ter apresentado o menor desvio-padrão da questão $(1,24)$ mostra que foi o fator que teve menos variação nos graus de importância a ele conferidos, o que reforça a sua primeira colocação.

Em tempos de NPM, governança, accountability e outros, é alvissareiro constatar que os gestores públicos enxergam a participação em organizações virtuais principalmente como forma de melhorar a qualidade dos produtos e serviços, e não apenas como forma de reduzir custos (terceiro lugar, com 20,5\%), cumprir orientação do governo (quinto lugar, com $22,7 \%$ ) ou simplesmente aumentar a produtividade (quarto lugar, 21,2\%).

Na seqüência decrescente de importância, em segundo lugar foi registrado o fator "compartilhamento de informações", com 19,6\% e o segundo maior desvio-padrão da questão $(1,45)$, o que indica que houve menor convergência de opiniões em relação a esse item. Ainda assim, pode-se afirmar que o entendimento da importância do compartilhamento de informações como fator de estímulo à participação em organizações virtuais, à frente de clássicas preocu- pações gerenciais, como custos, hierarquias e alocação de recursos, reflete uma conscientização dos gestores quanto aos benefícios que um ambiente informacional cooperativo pode proporcionar aos parceiros de uma organização virtual.

Destaque-se que apesar do item "redução de custos" ter ficado apenas em terceiro lugar, com $20,5 \%$, ele apresentou o maior desvio-padrão $(1,49)$, indicando que foi o fator percebido de forma mais heterogênea pelos gerentes-executivos, refletindo, assim, que o assunto encontra diversas acolhidas no seio da gestão pública.

Já o fator "aumento da produtividade", com $21,2 \%$ foi o fator que apresentou o segundo menor desvio-padrão $(1,26)$, indicando, assim, baixa variação da percepção de sua importância. Assim, os gestores consideram que o aumento da produtividade deve ser objeto de atenção gerencial, mas o mais importante é que ele esteja enquadrado em um escopo de melhoria dos produtos/serviços, e não percebido como algo a ser buscado como um fim em si mesmo.

O fator "cumprimento de orientação geral do governo", que recebeu 22,7\% dos pontos possíveis, apesar de ter ficado em último lugar como fator de estímulo à participação em organizações virtuais, apresentou desvio-padrão de 1,43, indicando que houve maior variação na percepção de sua importância.

Os resultados demonstram maior preocupação dos gestores com as demandas da sociedade, que será impactada em última instância pelos produtos e serviços gerados ou providos pelas organizações públicas, e com os ganhos proporcionados por um ambiente informacional cooperativo, em lugar de concentrar a atenção apenas em custos, hierarquias e alocação de recursos. 
A questão 17 registrou as percepções dos gerentes-executivos sobre a importância de fatores para o sucesso de uma organização virtual, tendo o fator "estratégia e objetivos bem definidos e adequadamente divulgados" sido apontado como o mais importante, com apenas 17,0\% dos pontos possíveis, embora o desvio-padrão de 1,34 não indique maior convergência de opiniões.

O fato de os gestores colocarem a necessidade de definição e adequada divulgação de estratégias e objetivos como o fator mais importante, à frente de aspectos formais, mostra uma visão gerencial que alcança além de ritos e rituais. Antes de planos e controles, é preciso haver cuidadosa definição de estratégias e objetivos, e não descuidar de sua adequada divulgação, ainda mais quando se trata de arranjos colaborativos, com várias organizações e diversos interesses em jogo.

O segundo lugar em importância atribuído ao fator "confiança entre os parceiros", com 18,8\%, suscita algumas ponderações, inclusive com relação ao princípio constitucional da impessoalidade, que deve reger a administração pública. Poder-se-ia afirmar que, do ponto de vista legal, a confiança não poderia ser jamais a base de arranjos colaborativos no setor público, pois não estaria ao alcance do gestor público a discricionariedade de confiar ou não em outro, pois a relação seria sempre "impessoal", regida por regras formalmente estabelecidas.

Não é o que pensam os gerentesexecutivos, que conseguem enxergar a importância de estratégias, objetivos e confiança para além de formalismos e regras. Isso é corroborado pela ocupação da terceira colocação em importância do fator "compromisso com a parceria", com $19,7 \%$ e o menor desvio-padrão
$(1,22)$, bem à frente do fator "contratos interorganizacionais formais detalhando as responsabilidades de cada participante", com 23,2\%, e colocado na última posição em importância, ainda que com o maior desvio-padrão $(1,51)$, indicando que sobre o assunto houve opiniões mais controvertidas.

A quarta colocação do fator "percepção dos parceiros de que os benefícios superam os custos e a relativa perda de autonomia", com 21,3\%, ainda que lhe tenha sido associado o segundo maior desvio-padrão $(1,44)$, indica que os gestores estão mais preocupados com estratégias, objetivos, confiança e compromisso, do que com a contabilização de "retorno sobre o investimento" e a proteção das fronteiras de seus feudos, o que vai ao encontro de uma gestão pública que prioriza resultados e não controles e poder.

Destaque-se o último lugar conferido ao fator "contratos interorganizacionais formais detalhando as responsabilidades de cada participante", quando um dos princípios que regem a administração é justamente o da legalidade, que prevê menor discricionariedade na ação do gestor público, que deve ser orientada por normas e regulamentos formais.

A última colocação em importância relativa para o fator, entretanto, demonstra que o foco não deve estar nos controles, que são necessários, mas que não podem passar a impressão de que os problemas no setor público se resumem a questões meramente técnicas e formais, sendo apenas necessário intensificar o uso de controles para aprimorar a gestão, quando, na verdade, muitos dos problemas são inerentemente políticos, afetados por valores sociais conflitivos e em mutação.

A questão 18 registrou as percepções dos gerentes-executivos sobre a importância 
de estratégias que poderiam ser desenvolvidas para aumentar o nível de comprometimento das organizações envolvidas em uma organização virtual. A estratégia considerada mais importante foi "implementar política de comunicações abertas e freqüentes" com 16,7\% e um dos dois menores desvios-padrão $(1,28)$ entre os cinco itens.

O primeiro lugar em importância atribuído à comunicação como forma de fomentar o compromisso dos parceiros encontra correspondência com o também primeiro lugar da questão 17 , que inclui a divulgação da estratégia e dos objetivos como o fator mais importante para o sucesso de uma organização virtual.

Para os gestores, então, comunicar é mais importante que mensurar, ainda que a mensuração tenha ficado em segundo lugar em importância, com o item "implementar sistemas que permitam a efetiva mensuração da contribuição de cada um dos parceiros na busca dos objetivos comuns" recebendo 19,5\%. Registre-se, porém, a diferença entre os dois desvios-padrão (1,28 para o primeiro lugar e 1,56 para o segundo), o que indica maiores diferenças de opinião entre os pontos atribuídos à mensuração do que entre os pontos atribuídos à comunicação.

A necessidade de mensuração está relacionada à percepção dos parceiros sobre os ganhos e perdas com a parceria, que, como já comentado, precisa ser objeto de contínua avaliação. Adicionalmente, podem-se citar os problemas relacionados à accountability gerados pelos novos arranjos interorganizacionais, devidos às relações muitas vezes "horizontais" entre as organizações envolvidas, afastando-se das relações hierárquicas implícitas no conceito tradicional de accountability.
Os três últimos itens receberam pontuação semelhante $(21,1 \%, 21,4 \%$ e $21,4 \%)$. Assim, na questão 18, diferentemente do que ocorreu nas questões 16 e 17, não houve claramente "um último colocado em importância”, com os temas provimento de recursos, relações interpessoais e treinamento e desenvolvimento "embolados".

Os itens que tratam dos temas "treinamento e desenvolvimento" e "provimento de recursos" são percebidos a partir de conjuntos mais homogêneos de opiniões (desvios-padrão de 1,28 e 1,29, respectivamente), com pequena vantagem em termos de grau de importância para o provimento de recursos. Já o item sobre relações interpessoais, que ficou em quarto lugar, diferencia-se do terceiro e quinto lugares pelo maior desvio-padrão $(1,53)$, indicando menor convergência de opiniões.

Associando-se essa menor convergência de opiniões sobre a importância das relações interpessoais com as respostas sobre a importância da confiança e do compromisso registradas na questão 17 , pode-se afirmar que para muitos gestores as relações interpessoais são muito importantes. De fato, navegando analiticamente pelos dados, foi constatado que 34 gestores $(21,8 \%$ do total de gestores) consideraram esse item como o mais importante, contra 45 que o consideraram como o menos importante (28,8\% do total de gestores).

Já a última questão (19) captou a percepção dos gerentes-executivos quanto à importância de estratégias que poderiam ser desenvolvidas para aumentar as chances de sucesso de uma organização virtual no setor público. O primeiro lugar em importância foi registrado para o item "estabelecer objetivos comuns a serem alcançados apenas por meio de trabalho 
cooperativo", que alcançou o percentual de $14,6 \%$ e um desvio-padrão de 1,26.

O maior percentual em termos de importância entre os quatro primeiros lugares das questões 16 a 19, o fato de apresentar um dos dois menores desviospadrão da questão em que está inserido, e a distância percentual que o separa do segundo colocado (a maior entre todas as distâncias anotadas nos 20 itens das quatro questões) confirmam o primeiro lugar da estratégia em destaque.

Com isso, os gerentes-executivos expressam uma convicção de que organização virtual no setor público aumentará suas chances de sucesso se de fato todos os parceiros colocarem "a mão na massa" para que os objetivos sejam alcançados. Dessa forma, deverão ser evitados objetivos difusos, que não permitam ou dificultem a individualização da contribuição de cada organização, e objetivos "personalizados", que possibilitem às organizações desenvolverem e implementarem seus planos de ação à margem da parceria.

A importância conferida a esse item, combinada com a importância registrada para "estratégia e objetivos bem definidos e adequadamente divulgados", primeiro lugar da questão 17, permite afirmar que os gestores entendem uma boa definição de objetivos como aquela que evite a prevalência de feudos e privilegie comportamentos cooperativos.

O segundo lugar em importância conferido ao item "prover infra-estrutura tecnológica adequada", com 19,1\%, é coerente com o alto grau de discordância registrado na questão 11 da Parte II (62,2\%), com relação à adequação da infraestrutura tecnológica para a implementação de práticas cooperativas de trabalho por meio de parcerias. Afinal, se os objetivos a serem estabelecidos devem ser "alcançados por meio de trabalho cooperativo", e a percepção é que a infra-estrutura não está adequada, então é importante prover a infra-estrutura tecnológica adequada.

O item acerca da "harmonização de estruturas organizacionais e de políticas de pessoal", ocupou o terceiro lugar em importância, com 20,5\%, registrando o maior desvio-padrão da questão $(1,48)$. $O$ alto desvio-padrão indica maior divergência de opiniões dos gerentesexecutivos sobre a importância do item. Aprofundando o estudo sobre essa divergência, foi constatado que 31 gestores $(19,9 \%)$ indicaram o item como o mais importante, e 39 (25,0\%) indicaram como o menos importante, confirmando que a opção por alterar estruturas e políticas de pessoal encontra diferentes acolhidas entre os gestores.

O quarto lugar conferido à importância da integração das "parcelas dos orçamentos das organizações envolvidas de modo a permitir uma gestão compartilhada do orçamento da organização virtual", com 22,0\%, ainda que com o segundo mais alto desvio-padrão da questão (1,38), o que significa divergências de percepção, reforça o primeiro lugar apontado pelos gestores, que sugere que o foco para o sucesso de uma organização virtual no setor público não está nos controles, mesmo orçamentários, e sim no estímulo ao trabalho cooperativo.

O último lugar em importância foi conferido ao item que trata da implementação de "sistemas de auditoria e de avaliação de desempenho organizacional que estimulem práticas cooperativas", que obteve o maior percentual $(23,9 \%)$ entre todos os 20 itens das questões 16 a 19, e um dos quatro menores desvios-padrão $(1,26)$. As práticas cooperativas, assim, na 
opinião dos gestores, devem ser estimuladas pelo trabalho a ser desenvolvido para alcançar objetivos comuns, e não por meio de sistemas de auditoria.

Não que tais sistemas não sejam importantes, mas é importante que tais sistemas contenham elementos que ajudem a desenvolver um tipo de senso de responsabilidade coletiva em relação ao trabalho, como os gestores consideram que pode acontecer com o estabelecimento de objetivos comuns, levando a uma congruência entre estratégia, objetivos, planos e avaliação.

\section{Conclusões}

O processo de planejamento governamental, desde a sua formulação até a sua implementação e avaliação, acontece em meio a uma rede de relacionamentos interorganizacionais, que envolve organizações públicas, organizações representativas de segmentos da sociedade, organizações não-governamentais e empresas privadas, o que provoca impactos na gestão em função de fatores culturais, sociais e tecnológicos.

Para incrementar a efetividade desse processo de gestão, é preciso fazer uso de estratégias que aumentem a capacidade do governo de fazer face às demandas da sociedade, sem onerá-la com mais impostos. Uma possibilidade seria a aplicação no setor público do conceito de organizações virtuais, já utilizado no setor privado.

De fato, os novos arranjos colaborativos que estão surgindo trazem implicações para o próprio conceito de organização, que, se é mantido em sua essência como fenômeno que acontece quando o trabalho de diversas pessoas precisa ser coordenado para atingir determinados objetivos, muda radicalmente em sua forma, uma vez que há profundas modificações nas idéias sobre fronteiras organizacionais, propriedade de recursos e processo decisório.

Nesse sentido, as organizações virtuais continuam representando a estruturação do trabalho em algum tipo de rede, mas, diferentemente do que ocorre nas organizações tradicionais, as novas organizações operam necessariamente a partir do compartilhamento de recursos e de objetivos de organizações formalmente independentes, o que requer lidar com diferentes impressões sobre autonomia, poder, e controle, frutos de diferentes culturas organizacionais.

De concreto, porém, e a despeito da retórica oficial, enfatizar a colaboração e a parceria entre as organizações públicas é fato em que persistem fortes tradições de independência, que reforçam a fragmentação da ação governamental. Apesar das recentes tentativas de aperfeiçoamento do modelo de planejamento, persistem superposições e incompatibilidades entre o modelo de gestão por programas e a estrutura hierárquica formal, o que gera conflitos de competência e dificulta a otimização do processo decisório.

Assim, apesar de ser expressão comum dos documentos e discussões relativos ao planejamento governamental, a coordenação é dificultada pelo caráter insular da administração pública, arquipélago de siglas e territórios demarcados. É preciso passar da visão de arquipélago para a visão de continente, por meio da qual o cidadão tivesse acesso aos serviços sem precisar conhecer sobre estruturas e fronteiras organizacionais.

Porém, encarar um programa, no conceito adotado no PPA, como uma organização virtual implica mais que apenas a alocação formal de recursos a contas contábeis. É preciso submeter os 
processos decisório, de monitoramento e de prestação de contas a um comando único em uma nova organização (virtual), criada, mantida e desenvolvida com a participação e o comprometimento das organizações parceiras, que a percebem não como estorvo administrativo ou mais um aparelho de controle, mas como forma de conseguirem alcançar objetivos comuns que nenhuma delas estaria em condições de alcançar sozinha, dentro de determinados padrões de qualidade, custo e tempo.

A colaboração, então, deve começar pelo entendimento das necessidades da sociedade de forma holística, e, para isso, a gestão cooperativa da informação pode contribuir para mitigar disputas por poder e territórios. Significa, então, que os gestores públicos precisam interagir com um ambiente informacional coope- rativo, no qual a informação requerida estaria disponível independentemente da estrutura hierárquica e de eventuais diferenças tecnológicas dos sistemas que fornecem a informação.

Por fim, cabe enfatizar que tais arranjos colaborativos não são apenas tendência, "novo rótulo para velhas práticas" ou novo modismo - representam desafios concretos que o governo precisa vencer para tornar realidade. Em uma dimensão menor, o discurso favorito da dita "nova gestão pública": fazer mais com menos; e, em uma dimensão maior, fazer valer a razão de ser dos governos: promover o bem-estar social e a igualdade de oportunidades.

(Artigo recebido em 13de agosto de 2007. Versão final em 29 de outubro de 2007)

\section{Nota}

${ }^{1}$ Os resultados apresentados e analisados fazem parte da tese de doutorado do autor, defendida em 2005 no âmbito do Programa de Pós-Graduação em Ciência da Informação da Universidade de Brasília.

\section{Referências bibliográficas}

Agranoff, Robert; Mcguire, Michael. Collaborative public management. new strategies for local governments. Washington, DC: Georgetown University Press, 2003.

Aladiwani, A. M. An empirical examination of the role of social integration in system development projects. Information Systems Journal, v. 12, n. 4, p. 339-353, Oct., 2002.

Albertin, Alberto Luiz. Administração de informática: funções e fatores críticos de sucesso. São Paulo: Atlas, 1999. 
Alecian, Serge; Foucher, Dominique. Guia de gerenciamento no setor público. Tradução de Márcia Cavalcanti. Rio de Janeiro: Revan; Brasília: ENAP, 2001.

Allen, D. K.; Colligan, D.; Finnie, A.; Kern, T. Trust, power and inter-organizational information systems: the case of the Electronic Trading Community Translease. European Journal of Information Systems, v.10, n. 1, p. 21-41, 2000.

Allen, David; WiLson, Tom. Vertical trust/mistrust during information strategy formation. International Journal of Information Management, v. 23, n. 3, p. 223-237, Jun., 2003.

Altheide, David L., Johnson, John M. Criteria for assessing interpretative validity in qualitative research. In: Denzin, Norman K.; Lincoln, Yvonna S. (Ed.). Strategies of qualitative inquiry. London: Sage, p.283-312, 2003.

Andrulis, Jeremy; Hirning, Kate. Collaborative government services: building the future. New York: Institute for Business Value - IBM, 2002.

Arcieri, F.; Cappadozzi, E.; Naggar, P.; Nardelli, E.; Talamo, M. Coherence maintenance in cooperative information systems: the access key warehouse approach. International Journal of Cooperative Information Systems, v. 11, n. 3, 4, Sept./Dec., 2002.

Arvidson, Göran. Collaboration by contract e pooling resources: the implications for evaluation. In: Gray, Andrew; Jenkins, Bill; LeEnw, Frans; MAYne, John (Ed.). Collaboration in public services: the challenge for evaluation. New Brunswick: Transaction, 2003.

Austin, James E. Meeting the collaboration challenge workbook. New York: Peter F. Drucker Foundation for Nonprofit Management ; Dorchester: James E. Austin, 2002c.

Baker, D.; Georgakopoulos, D.; Schuster, H.; Cichocki, A. Awareness provisioning in collaboration management. International Journal of Cooperative Information Systems, v. 11, n. 3, 4, Sept./Dec., 2002.

Bemelmans-Videc, Marie-Louise. Auditing e evaluating collaborative Government: the role of supreme audit institutions. In: Gray, Andrew; Jenkins, Bill; LeEnw, Frans; MAYNe, John (Ed.). Collaboration in public services: the challenge for evaluation. New Brunswick: Transaction, 2003.

Bıo, Sérgio Rodrigues. Sistemas de informação: uma visão gerencial. São Paulo: Atlas, 1996. Boston, Jonathan. Lessons from the Antipodes. In: O’Toole, Barry J.; Jordan, Grant (Ed.). Next steps: improving management in government. Hants: Ipswich Book, p. 161177, 1995.

Bower, Joseph L. The Velcro organization. Harvard Business Review, p. 6-7. Feb., 2005. Bowersox, Donald J. Os benefícios estratégicos das alianças logísticas. In: Estratégia: a busca da vantagem competitiva. Rio de Janeiro: Campus, p. 331-346, 1998.

BoYLE, Richard. A partnership approach to change: the civil service reform programme in the Republic of Ireland. In: Nolan, Brendan C. (Ed.). Public sector reform: an international perspective. Hampshire (UK): Palgrave, p. 49-65, 2001.

Bradner, Erin. Computer mediated communication among teams: what are "teams" and how are they "virtual"? From UseNet to CoWebs: interacting with social information spaces. London: Springer-Verlag, editado por Chistopher Lueg and Danyel Fisher, 2003. 
BRASIL. Constituição (1988). Constituição da República Federativa do Brasil: promulgada em 5 de outubro de 1988: atualizada até a Emenda Constitucional n 20, de 15-12-1998. 21. ed. São Paulo: Saraiva, 1999.

Brasil. Escola Nacional de Administração Pública. Relatório de pesquisa. Brasília, 2000. Brasil. Ministério do Planejamento, Orçamento e Gestão. PPA tem novo modelo de gestão (8/10/2004). Disponível em www.planobrasil.gov.br. Acesso em 4 maio 2005. Brasil. Ministério do Planejamento, Orçamento e Gestão. Secretaria de Planejamento e Investimentos Estratégicos. O desafio do planejamento governamental. Brasília, 2002.

BrasiL. Ministério do Planejamento. Secretaria de Planejamento e Investimentos Estratégicos. Manual de elaboração do plano gerencial dos programas do PPA 2004-2007. Brasilia, 2004.

BURNETT, Gary. Information exchange in virtual communities: a typology. Information Research, v. 5, n. 4, 2000. Disponível em http://informationr.net/ir/5-4/paper82.html. Acesso em novembro de 2003.

Camarinha-Matos, L. M.; Afsarmanesh, H; Rabelo, R. Supporting agility in virtual enterprises. In: Working Conference ON Infrastructures For Virtual Organisations, 2., 2000, Florianópolis. Anais. Massachusetts: Kluwer Academic, IFIP - International Federation for Information Processing, p.89-104, 2001.

Calmon, Kátya Maria Nasiaseni; Gusso, Divonzir Arthur. A experiência de avaliação do Plano Plurianual (PPA) do Governo Federal do Brasil. Oficina de trabalho do Projeto "Fortalecimento da função avaliação na América Latina", promovida por Ipea e Cepal. 23 e 24-outubro de 2003, Santiago do Chile.

Campos, Roberto. A lanterna na popa... Rio de Janeiro: Topbooks, 1994.

Carbo, J.; Molina, J. M.; Davila, J. Trust management through fuzzy reputation. International Journal of Cooperative Information Systems, v. 12, n. 1, p. 135-155, Mar., 2003.

CAstelfranchi, C. The social nature of information and the role of trust. International Journal of Cooperative Information Systems, v. 11, n. 3, 4, p. 211-241, Sept./Dec., 2002.

Castellani, Stefania; Andreoli, Jean Marc; Bratu, Mihnea; Boissier, Olivier, Alloui, Ilham; Megzari, Karim. E-Alliance: a negotiation infrastructure for virtual alliances. In: Group Decision and Negotiation Journal. The Netherlands: Kluwer Academic, v.12, Issue 2, p. 127-141, Mar., 2003.

Castells, Manuel. A sociedade em rede. Tradução de Roneide Venancio Majer. São Paulo: Paz e Terra, 1999.

Castells, Manuel. Hacia el Estado Red? Globalizacion economica e instituciones politicas en la era de la información. In: Seminário Internacional Sociedade e a Reforma do Estado, 1998, São Paulo. Anais ... São Paulo: Ministerio de Administracao Federal e Reforma do Estado, 1998.

Cheunga, Sai-On. Behavioral aspects in construction partnering. International Journal of Project Management, v. 21, p. 333-343, 2003.

CHOO, Chun W. Information management for the intelligent organization: roles and implications for the information professions. New Jersey: ASIS, 1998. 
Colman, Robert. Ottawa's change agent. BetterManagement.com. Disponível em: <www.bettermanagement.com>. Acesso em 21 de março de 2005.

DALEY, Dennis M.; VASU, Michael L. Supervisory perceptions of the impact of public sector personnel practices on the achievement of multiple goals: putting the strategic into human resource management. The American Review of Public Administration, v. 35, n. 2, p. 157-167, Jun., 2005.

Davenport, Thomas H. Ecologia da informação. Tradução de Bernadette Siqueira Abrão. São Paulo: Futura, 1998.

Devine, Mary; Filos, Erastos. Virtual teams and the organisational grapevine. In: Working Conference on Infrastructures for Virtual Organizations, 2., 2000, Florianopolis. Anais. Massachusetts: Kluwer Academic, 2001. IFIP - International Federation for Information Processing.

Dunsire, Andrew. Implementation theory and bureaucracy. In: Younis, Talib (Ed.). Implementation in Public Policy. Hants: Dartmouth Publishing, p. 15-30, 1990.

EIN-Dor, Philip; SEgev, Eli. Administração de sistemas de informação. Tradução de Marina Cunha Brenner. Rio de Janeiro: Campus, 1986.

Filos, E.; Banahan, E. Will the organisation disappear? The challenges of the new economy and future perspectives. In: Working Conference on Infrastructures for Virtual Organizations, 2., 2000, Florianopolis. Anais. Massachusetts: Kluwer Academic, 2001. IFIP - International Federation for Information Processing.

FINANÇAS públicas: $7^{\circ}$. prêmio Tesouro Nacional, 2002. Brasília: Ed. Universidade de Brasília, 2003. Coletânea de monografias.

Glendinning, Caroline. Breaking down barriers: integrating health and care services for older people. England. Health Policy, v. 65, n. 2, p. 139-151, Aug., 2003.

GorAnson, H. T. Infrastructure for the advanced virtual enterprise: a report using a Brazilian-based example. In: Working Conference on Infrastructures for Virtual Organizations, 2., 2000, Florianopolis. Anais. Massachusetts: Kluwer Academic, 2001. IFIP - International Federation for Information Processing.

Gray, Andrew; Jenkins, Bill; Leenw, Frans; Mayne, John (Ed.). Collaboration in public services: the challenge for evaluation. New Brunswick: Transaction, 2003a.

Greenhalgh, Leonard. Managing strategic relationships: the key to business success. New York: Free Press, 2001.

Gregor, S.; Johnston, R.B. Developing an understanding of interorganizational systems: arguments for multi-level analysis and structuration theory. In: Proceedings of European Conference on Information Systems, 8., 2000, Vienna, Austria. Proceedings, 2000.

Gresham, Maria T.; ANDrulis, Jeremy. Optimization of information to improve decision making in government: the information value chain way. New York: Institute for Business Value ; IBM, 2002.

Hunt, Michael. The employment service as an agency: the first three years. In: O'TOOLE, Barry J.; Jordan, Grant (Ed.). Next steps: improving management in government. Hants: Ipswich Book, p. 74-85, 1995. 
InKPen, Andrew C.; Ross, Jerry. Why do some strategic alliances persist beyond their useful life? California Management Review, Vol. 44, n.1, p. 132-148, 2001.

Jannuzzi, Paulo de Martino. Indicadores para diagnóstico, monitoramento e avaliação de programas sociais no Brasil. Revista do Serviço Público, Brasília, v. 56, n. 2, p. 137-160, abr./jun., 2005.

JóIA, Luiz Antonio. Inteligência também se constrói. HSM Management Update, n. 18, mar., 2005.

Kaplan, Robert S.; NorTon, David P. Ligando a estratégia ao planejamento e orçamento. In: Balanced Scorecard Collaborative. Disponível em: <www.symnetics.com.br/news/ detalhe.asp?id=26>. Acesso em $1^{\circ}$ de julho de 2005.

Kincheloe, Joe L.; Mclaren, Peter L. Rethinking critical theory and qualitative research. In: Denzin, Norman K.; Lincoln, Yvonna S. (Ed.). Strategies of qualitative inquiry. London: Sage, 2003a.

Kolekofski, Keith E.; Heminger, Alan R. Beliefs and attitudes affecting intentions to share information in an organizational setting. Information \& Management, v. 40, n. 6 , p. 521-532, Jul., 2003.

KotLARSKY, Julia; Oshri, Ilan. Social ties, knowledge sharing and successful collaboration in globally distributed system development projects. European Journal of Information Systems, v. 14, p. 37-48, 2005.

Kunn, Thomas S. A estrutura das revoluções científicas. Tradução de Beatriz Vianna Boeira; Nélson Boeira. São Paulo: Perspectiva, 1982.

Lagace, M. How to put meaning back into leading. Harvard Business School Working Knowledge. Disponível em www.bettermanagement.com. Acesso em 18 de maio de 2005.

LeE, Hau L. The triple-A supply chain. Harvard Business Review, Oct., 2004.

LevitT, Ruth. Implementing Public Policy. London: Croom Helm, 1980. 213 p.

Loegreid, Per. Administrative reforms in Scandinavia - testing the cooperative model. In: Nolan, Brendan C. (Ed.). Public sector reform: an international perspective. Hampshire (UK): Palgrave, p. 66-82, 2001.

MAndell, Myrna P. Network management: strategic behaviour in the public sector. In: Gage, Robert; Manning, Peter K; Cullum-Swan, Betsy. Narrative, content and semiotic analysis. In: Denzin, Norman K.; Lincoln, Yvonna S. (Ed.). Strategies of qualitative inquiry. London: Sage, 2003a.

Marini, Caio; Martins, Humberto. Um governo matricial: estruturas em rede para geração de resultados de desenvolvimento. In: Congreso Internacional del Clad sobre la Reforma del Estado y de la Administración Pública, 9. Madrid, España. 2004.

Marteleto, Regina Maria; Silva, Antonio Braz de Oliveira e. Redes e capital social: o enfoque da informação para o desenvolvimento local. Ciência da Informação, Brasília, v. 33, n. 3, p. 41-49, set./dez., 2004.

Martin, Roger L. Seek validity, not reliability. Harvard Business Review, Feb., 2005. 
Martins, Humberto Falcão. Introdução ao governo matricial: o problema da fragmentação. In: Congreso Internacional del Clad sobre la Reforma del Estado y de la Administración Pública, 9. Madrid, España. 2004.

Mattar, F. Pesquisa de marketing. São Paulo: Atlas, 1997.

MAYNE, John. Results-based governance: collaborating for outcomes. In: GrAY, Andrew; Jenkins, Bill; LeEnw, Frans; Mayne, John (Ed.). Collaboration in public services: the challenge for evaluation. New Brunswick: Transaction, 2003.

Mayne, John; Wileman, Tom; Leenw, Frans. Networks and partnering arrangements: new challenges for evaluation and auditing. In: Gray, Andrew; Jenkins, Bill; LeENw, Frans; MAYNE, John (Ed.). Collaboration in public services: the challenge for evaluation. New Brunswick: Transaction, 2003.

Meirelles, Anthero de Moraes. Trabalhos para discussão. Brasília: Banco Central do Brasil, n.56, ago., 2005. Disponível em www.bcb.gov.br/pec/wps/port/wps96.pdf. Acesso em 9 de setembro de 2005.

Merali, Y. The role of boundaries in knowledge process. European Journal of Information Systems, v. 11, n. 1. p. 47-60. Mar., 2002.

Ministério do Planejamento. Governo vai intensificar execução de programas. Disponível em www.planejamento.gov.br/planejamento_investimento/conteudo/noticias/noticia2005/051017_governo_intensifica.htm. Acessado em 20 de outubro de 2005.

MintzBerg, Henry. A criação artesanal da estratégia. In: Estratégia: a busca da vantagem competitiva. Rio de Janeiro: Campus, p. 419-437, 1998.

Molina, Arturo; Flores, Myrna. Exploitation of business opportunities: the role of the virtual enterprise broker. In: Working Conference on Infrastructures for Virtual Organizations, 2., 2000, Florianopolis. Anais. Massachusetts: Kluwer Academic, 2001. IFIP - International Federation for Information Processing.

Montgomery, Cynthia A.; PORTER, Michael (Org.). Estratégia: a busca da vantagem competitiva. Rio de Janeiro: Campus, 1998.

Morgan, Crawford. Asbestos policy and practice in a local authority. In: Younis, Talib (Ed.). Implementation in Public Policy. Hants: Dartmouth Publishing, p. 40-52, 1990.

Morrison, James; WiLSON, Ian. The strategic management response to the challenge of global change. Disponível em http:/ / horizon.unc.edu. Acesso em 21 de março de 2005. Mundim, Ana Paula Freitas; Bremer, Carlos Frederico. Design of a computer-supported cooperative environment for small and medium enterprises. In: Working Conference on Infrastructures for Virtual Organizations, 2., 2000, Florianopolis. Anais. Massachusetts: Kluwer Academic, 2001. IFIP - International Federation for Information Processing. Mutschke, Peter; HaAse, Anabel Quan. Collaboration and cognitive structures in social science research field: towards socio-cognitive analysis in information systems. Scientometrics, Dordrecht, v.52, n.3, p. 487-502, 2001.

NorTon, David P. Managing strategy is managing change. Balanced Scorecard Report. v. 4, n. 1, Jan./Feb., 2002. 
Oliveira, Ely Francina Tannuri; Grácio, Maria Cláudia Cabrini. Análise a respeito do tamanho de amostras aleatórias simples: uma aplicação na área de Ciência da Informação. DataGramaZero. v.6, n.3, Jun., 2005.

PAinter, Chris. The next steps reforms and current orthodoxies. In: O'TOOLE, Barry J.; Jordan, Grant (Ed.). Next steps: improving management in government. Hants: Ipswich Book, p. 17-36, 1995.

PORTER, Michael E. Da vantagem competitiva à estratégia corporativa. In: Estratégia: a busca da vantagem competitiva. Rio de Janeiro: Campus, 1998c. p. 237-269.

Prahalad, C. K.; Krishnam, M. S. The new meaning of quality in the information age. Harvard Business Review, local, v. 77, n. 5, p. 109-118, Sep./Oct., 1999.

Ricci, A.; Omicini, A.; Denti, E. Virtual enterprises and workflow management is agent coordination issues. International Journal of Cooperative Information Systems, v. 11, n. 3/4, p. 355-380, Sept./Dec., 2002.

Richards, David; Smith, Martin J. Governance and publicpolicy in the United Kingdom. Oxford: Oxford University Press, 2002.

Richardson, Roberto Jarry. Pesquisa social: métodos e técnicas. São Paulo: Atlas, 1999.

RiEMPP, Gerold. Wide area workflow management: creating partnerships for the 21 st century. London: Springer-Verlag London, 1998.

SAVIANI, José R. O analista de negócios e da informação: o perfil moderno de um profissional que utiliza informática para alavancar os negócios empresariais. São Paulo: Atlas, 1998.

Schultze, Ulrike; Boland, Richard J. Place, space and knowledge work: a study of outsourced computer systems administrators. Accounting Management and Information Technologies. v. 10, n. 3, p. 187-219, Jul., 2000.

SCHWARTZ, Robert. The politics of evaluating government collaboration with the third sector. In : Gray, Andrew; Jenkins, Bill; Leenw, Frans; Mayne, John (Ed.). Collaboration in public services: the challenge for evaluation. New Brunswick: Transaction, 2003.

SEgsworth, Bob. Evaluation accountability and collaboration. In: GraY, Andrew; JENKINS, Bill; LeENw, Frans; MAYNE, John (Ed.). Collaboration in public services: the challenge for evaluation. New Brunswick: Transaction, 2003.

Shimizu, Tamio. Processamento de dados: conceitos básicos. São Paulo: Atlas, 1994.

Shumar, Wesley; Renninger, K. Ann. On conceptualizing community: building virtual communities: learning and change in cyberspace. Cambridge: Cambridge University Press, editado por K. Ann Renninger, Wesley Shumar, 2002.

Silva, Benedicto. Uma teoria geral de planejamento. Rio de Janeiro: Escola Brasileira de Administração Pública : Fundação Getúlio Vargas, 1964.

Silva, Nuno; Rocha, João. VE infrastructures requirements for cooperation and knowledge sharing. In: Working Conference on Infrastructures for Virtual Organizations, 2., 2000, Florianópolis. Anais. Massachusetts: Kluwer Academic, 2001. IFIP - International Federation for Information Processing.

Sink, D. Scott; TutTie, Thomas C. Planejamento e medidas para a performance. Tradução de Elenice Mazzili e Lúcia Faria Silva. Rio de Janeiro: Qualitymark Ed, 1993. 
STAUFFER, David. Is your benchmarking doing the right work? Harvard Management Update, v. 8, n. 9, Sept., 2003.

Tristão, Gilberto. Planejamento: enfoque tridimensional. Rio de Janeiro: Livros Técnicos e Científicos, 1978.

VAsu, Michael L.; Stewart, Debra W.; Garson, G. David. Organizacional behaviour and public management. 3rd. ed. rev and expanded. New York: Marcel Dekker, 1998.

Waterman JR, Robert H. Adhocracia: o poder para mudar. Tradução de Carlos Afonso Malferrari. São Paulo: Pioneira, 1992.

WeIner, Norbert. Cibernética e sociedade: o uso humano dos seres humanos. Tradução de José Paulo Paes. São Paulo: Cultrix, 1968.

WeLCH Jr; J. General Electric. Annual Report 1995. 1996. Disponível em: <www.ge.com/ annual95/ibb3a18.htm>. Acesso em 27 de setembro de 2005.

Wilson, T.D. Recent trends in user studies: action research and qualitative methods. Berlin: Freie Universität, Institut fqr Publizistik und Dokumentationswissenschaft, 1980. (Projekt Methodeninstrumentarium zur Benutzerforschung in Information und Dokumentation, MIB P1 11/80). Disponível em http://InformationR.net/ir/ paper76.html. Accesso em novembro de 2003.

WiLson, Tom. Information science and research methods. Kni•nicná a informacná veda (Library and Information Science), published by the Department of Library and Information Science, Comenius University, Bratislava, Slovak Republic. Updated 26th March. 2002b.

Wright, Deil S. Federalism, intergovernmental relations and intergovernmental management - conceptual reflections, comparisons and interpretations. In: GAGE, Robert; Mandell, Myrna. (Ed.). Strategies for managing intergovernmental policies and networks. New York: Praeger, p. 151-180, 1990.

YIN, Robert K. Case study research: design and methods. London: Sage, 2003.

Younis, Talib; Davidson, Ian. The study of implementation. In: Younis, Talib (Ed.). Implementation in Public Policy. Hants: Dartmouth Publishing, 1990. p. 3-14.

Yourdon, Edward. Análise estruturada moderna. Tradução de Dalton Conde de Alencar. Rio de Janeiro: Campus, 1990. 


\section{Resumo-Resumen-Abstract}

Fatores e estratégias que impactam a aplicabilidade de organizações virtuais no setor público: a percepção dos gerentes-executivos do PPA

Henrique Flávio Rodrigues da Silveira

O trabalho apresenta e analisa os resultados de uma pesquisa de campo realizada junto aos gerentes-executivos de programas do Plano Plurianual (PPA) sobre a possibilidade de aplicação do conceito de organização virtual no setor público. Em uma organização virtual, os parceiros compartilham informações e infra-estrutura de maneira sinérgica, incrementando a efetividade para um nível que nenhum deles poderia alcançar sozinho. Nesta nova Era, tradicionais conceitos são abandonados ou questionados, e o próprio conceito de "organização" está mudando, de forma a refletir os desafios inerentes ao novo ambiente. O trabalho descreve e analisa o contexto que molda essa nova abordagem para o processo de planejamento governamental, e os resultados de pesquisa de campo, na qual foram avaliados os fatores e estratégias que impactam a coordenação interorganizacional requerida para o adequado funcionamento de uma organização virtual. Entre as conclusões, destaca-se a possibilidade de aplicação, no setor público, do conceito de organizações virtuais, as quais operam necessariamente a partir do compartilhamento de recursos, informações e de objetivos de organizações formalmente independentes, o que requer lidar com diferentes impressões sobre autonomia, poder e controle e diferentes culturas organizacionais, alterando, radicalmente, conceitos e práticas acerca de fronteiras organizacionais, propriedade de recursos, gestão da informação e processo decisório.

Palavras-chave: Organizações virtuais. Planejamento governamental. Coordenação interorganizacional.

Factores y estrategias que impactan la aplicabilidad de organizaciones virtuales en el sector público: la percepción de los gerentes ejecutivos del PPA

Henrique Flávio Rodrigues da Silveira

Este trabajo hace la presentación y el análisis de los resultados de una investigación de campo, junto a los gerentes ejecutivos de los programas del Plan Plurianual (PPA), sobre la posibilidad de aplicación del concepto de organización virtual en el área pública. En una organización virtual, los compañeros comparten informaciones e infraestructura de modo sinérgico, lo que incrementa la efectividad hacia un nível que ninguno de ellos sería capaz de conseguir solo. En esta nueva era, conceptos tradicionales son abandonados o cuestionados, y el próprio concepto de organización está cambiando, de modo a reflejar los nuevos desafios que hay en el nuevo ambiente. El trabajo hace la descripción y el análisis del contexto que moldea esta nueva forma de abordar el proceso de planificación guvernamental y de los resultados de la investigación de campo, en la que son evaluados los hechos y las estratégias que impactan la coordinación entre organizaciones, que es requerida para el adecuado funcionamiento de una organización virtual. Entre las conclusiones, se destaca la posibilidad de aplicación del concepto de organizaciones virtuales en el área pública, las cuales operan necesariamente a partir del compartir de recursos, informaciones y de objetivos de organizaciones formalmente independientes; lo que requiere ocuparse de las distintas impresiones sobre autonomía, poder, control y distintas culturas organizacionales, cambiando de forma radical los conceptos y prácticas de fronteras organizacionales, propiedad de recursos, gestión de la información y proceso decisorio.

Palabras-clave: Organización virtual. Planificación guvernamental. Coordinación entre organizaciones. 


\section{Factors and strategies that impact virtual organizations in the public sector: the perception of executive managers of the Puriannual Plan \\ Henrique Flávio Rodrigues da Silveira}

The paper describes and analyses the results of a field research, which was conducted with the executive-managers of the governmental planning programs (PPA), about the possibility of implementing the concept of virtual organization in the public sector. In a virtual organization, partners share information and infrastructure in a synergetic way, improving effectiveness to a level that none of the partners would be able to achieve alone. In this new Era, traditional concepts are being abandoned or questioned, and the concept of "organization" is itself changing, in order to reflect the challenges related to the new environment. The paper describes and analyses the context that shapes this new approach for the governmental planning, and the results of the field research, about the evaluation of the factors and strategies that impact the interorganizational coordination required by a virtual organization in order to succeed. Among the conclusions, there is the possibility of introducing the concept of virtual organisation in the public sector, which operates necessarily from the sharing of resources, information, and objectives of formally independent organisations; requiring dealing with different impressions about autonomy, power and control and different organisational cultures, changing, in a radical way, concepts and practices regarding organisational boundaries, ownership of resources, information management and decision making process.

Keywords: Virtual organization. Governmental planning. Interorganizational coordination.

Henrique Flávio Rodrigues da Silveira

É doutor em Ciência da Informação - Universidade de Brasília (UnB). Analista do Banco Central do Brasil e professor universitário. Contato: <henrique.silveira@bcb.gov.br> 